\title{
ARTIGOORIGINAL
}

\section{Explorando os metadados na recomendação de músicas em um ambiente com escassez de informação}

\section{Exploiting metadata for a song recommender system under scarce data}

\author{
Diego Corrêa da Silva ${ }^{\mathbb{D}, 1}$ and Frederico Araújo Durão ${ }^{\mathbb{D}, 1}$ \\ ${ }^{1}$ Universidade Federal da Bahia \\ *diego.correa@ufba.br; fdurao@ufba.br
}

Recebido: 07/20/2019. Revisado: 02/04/2020. Aceito: 18/05/2020.

\begin{abstract}
Resumo
O surgimento dos serviços de transmissão de música, produziu um efeito altamente lucrativo ao setor musical. Estes serviços se utilizam de sistemas de recomendação para encontrar faixas que venham a agradar aos usuários, coletando assim ricas informações a respeito do que ouvem. $\mathrm{O}$ volume de dados obtido possibilita um cenário rico em características que descrevem a ambos, fazendo, assim, com que as recomendações possam ser mais confiáveis. Entretanto, nem sempre é possível trabalhar com um ambiente rico em dados, levantando assim a pergunta, é possível um cenário com escassez de dados onde se encontrem recomendações para seus usuários? O problema que este trabalho visa resolver é a dificuldade que os sistemas de recomendação têm em sugerir novas obras para os usuários diante de um cenário com escassez de informação. Ao longo deste trabalho um levantamento teórico é realizado assim como os modelos necessários para o desenvolvimento do sistema. Os resultados evidenciam que é possível realizar recomendações em um cenário com escassez de informação. A avaliação mostra que em um ambiente desbalanceado onde apenas $11 \%$ das músicas são consideradas relevantes é possível obter, na métrica de precisão, aproximadamente $20 \%$ de assertividade ao longo das listas de recomendações, assim como uma lista de recomendação com um número maior de faixas ajuda na obtenção de um melhor resultado. A avaliação também mostra que é possível obter na métrica de reciprocidade mais de $35 \%$ de assertividade.
\end{abstract}

Palavras-Chave: Filtragem Baseada em Conteúdo; Metadados; Músicas; Sistema de Recomendação

\section{Abstract}

The emergence of music streaming services, produced a highly lucrative effect on the music sector. These services use recommendation systems to find tracks that will appeal to users, collecting rich information about them and what they listen to. The obtained volume of data enables an environment rich in characteristics that describe both, thus making recommendations more reliable. However, it is not always possible to work with an environment rich in data, thus raising the question, is it possible to find recommendations in a scenario with scarcity of data? The problem this work aims to solve is the difficulty recommendations systems have to suggesting new songs for users in front of an environment with scarcity information, exploring metadata combinations to find recommendations. Throughout this work a theoretical survey will be conducted, as well as the proposed system, the necessary models for development of the system. The results show it is possible to make recommendations in an environment with scarcity information. The evaluation show that, in an unbalanced environment where only $11 \%$ of songs are considered relevant it is possible to obtain, in the precision metric, approximately $20 \%$ of assertiveness along the recommendations lists, as well as a recommendation list with a larger number of songs helps to obtain a better result. The evaluation also showed it is possible to obtain more than $35 \%$ assertiveness in the reciprocal metric. 


\section{Introdução}

O surgimento dos serviços de transmissão de música, a partir dos anos 2000, produziu um efeito altamente lucrativo, impulsionando o crescimento do setor musical. No ano de 2016 empresas como Spotify, Apple Music, Youtube e Pandora, geraram um aumento de $11,4 \%$ no faturamento da indústria musical, chegando a uma receita de 7.7 bilhões, que é a maior alta desde 1998. Este crescimento vem aumentando ano após ano, sendo que nos últimos cinco anos estes serviços passaram de $9 \%$ para $51 \%$ do faturamento total da indústria musical (Estadão, 2017). Em 2017, os principais serviços de transmissão de música geraram 14,2 milhões de dólares por dia (News, 2018). Esses serviços também permitem o armazenamento interno de diversos tipos de informação, como por exemplo: os gostos musicais dos usuários, músicas mais ouvidas, artistas mais ouvidos, músicas preferidas em países e/ou continentes, dando assim a oportunidade de constante expansão para a área e satisfação para os usuários. No ano de 2015 os serviços supracitados ultrapassaram a marca de 1 trilhão de reproduções no ano (Forbes, 2015). O Spotify em 2015 teve 20 bilhões de horas de músicas reproduzidas, sendo mais de 20 mil faixas adicionadas diariamente, e em 2018 ultrapassou a quantidade de 30 milhões de músicas em seu catálogo (DMR, 2018). Não é difícil imaginar que num futuro próximo, tudo que for gravado estará disponível online e os serviços de música digital oferecerão bilhões de obras, com milhões a mais chegando a cada semana (Celma and Lamere, 2008).

Com tantas músicas disponíveis para serem escolhidas, a busca por músicas relevantes envolve o usuário em um esforço enorme, sendo que muitas vezes ele irá encontrar coisas que não agradem, criando assim uma sobrecarga de informação musical (Hijikata et al., 2006). É possível transferir este trabalho de encontrar trabalhos novos para um sistema automatizado, este que fique responsável por encontrar uma lista ranqueada de recomendações para cada usuário.

De acordo com Ricci et al. (2011), Sistemas de Recomendação são ferramentas de programas e técnicas que proveem sugestões de itens para os usuários. Estas sugestões são encontradas através de comparações entre itens e/ou usuários. Atualmente, sistemas de recomendação estão em diversos setores da Internet. Fields (2011) define Sistemas de Recomendação como uma técnica ou método que apresenta a um usuário objetos sugeridos para consumo com base em seu comportamento passado.

Para realizar seu trabalho, um Sistema de Recomendação de Música necessita de dados sobre as preferências dos usuários e das características que descrevem as músicas. Aplicações como o Last.fm e o Spotify possuem milhões de usuários e obras contendo diversas informações sobre ambos. Celma (2010) afirma que alguns sistemas chegam a utilizar mais de 400 atributos durante o processo de recomendação, trabalhando assim em um cenário rico de informações e possibilitando recomendações mais precisas. Na literatura de Sistemas de Recomendação é comum estudos que desejam enriquecer o cenário com dados provindos de diversas fontes (Web, redes sociais, contexto) para que assim as recomendações possam ser mais "úteis" aos usuários.

Entretanto o que acontece caso esses sistemas não possuam um cenário com riqueza de dados? Seria possível construir um sistema de recomendação que escolhesse músicas em um ambiente com escassez de informação? Quais abordagens esse sistema usaria? Como esses dados podem ser utilizados para encontrar as recomendações? É possível recomendar utilizando somente um metadado? Utilizar mais de um metadado na recomendação obtém melhora na precisão?

O problema que este trabalho visa resolver é a dificuldade que os sistemas de recomendação têm em fazer sugestões para os usuários diante de um cenário com escassez de informação disponível, tendo em vista que a busca manual por novas canções nem sempre é um trabalho agradável, requisitando do usuário tempo e concentração. A busca por uma nova música inicia-se a partir da peculiaridade musical do usuário, que escolhe uma informação para a busca de uma nova música ou pede recomendações a amigos e conhecidos, os quais irão recomendar músicas de suas preferências.

Este trabalho propõe como solução a criação de um sistema que, em um cenário com escassez de informação, analisa a similaridade de metadados que descrevem as mídias como título, artista e álbum, utilizando alguma técnica de recomendação, que irá auxiliar a gerar melhores recomendações após cada interação do sistema com os dados do usuário. Estas recomendações são personalizadas para cada usuário e listadas para que o mesmo possa avaliá-las. Os objetivos específicos do trabalho são:

- Recuperar e processar os metadados das músicas;

- Definir o modelo do usuário de acordo com o que foi ouvido ou que tenha expressado interesse;

- Propor um modelo de recomendação utilizando algum algoritmo de similaridade;

- Avaliar a proposta com uma base de dados pública;

As contribuições deste trabalho são: revisão da literatura; um sistema de recomendação de música que sugere uma lista com novas músicas para o usuário com a máxima similaridade em um ambiente com escassez de informação; a melhor combinação de metadados para serem usados na recomendação; avaliação experimental e uma discussão crítica dos resultados. Outra grande contribuição deste trabalho é afirmar que é possível construir um sistema de recomendação de música com escassez de metadados que descrevem as músicas. Entretanto é esperado que a escassez de metadados impacte a precisão do modelo.

O problema da partida a frio não é abordado neste trabalho, visto que estamos interessados em trabalhar com os metadados da música. O sistema usa uma base de dados disponibilizada pelo projeto Million Songs Dataset.

As próximas seções estão organizadas na seguinte sequência: A Seção 2, apresenta a base teórica. A Seção 3, apresenta o estado da arte na área e a definição da investigação. A Seção 4, apresenta a proposta: um 
sistema de recomendação de músicas baseado em conteúdo utilizando metadados textuais. A Seção 5 apresenta a metodologia de avaliação do sistema. A Seção 6 apresenta os resultados obtidos, e por fim a Seção 7 apresenta as conclusões e considerações finais.

\section{Sistemas de Recomendação}

Ricci et al. (2011) explicam que em sua forma mais simples, recomendações personalizadas são fornecidas como uma lista ordenada de itens candidatos. Para encontrar os itens que constituirão essa lista, sistemas de recomendação tentam predizer qual produto ou serviço mais agradará aos usuários, baseando-se nas suas preferências. Para isso, eles coletam os dados, que podem ser expressos explicitamente, por exemplo, nas avaliações de produtos ou serviços. Ou são inferidos interpretando as ações do usuário no sistema. $\mathrm{O}$ sistema pode considerar um acesso à página de um produto como um sinal implícito de preferência ou até comentário sobre um produto, por exemplo.

As pessoas frequentemente dependem de recomendações de outras, seja através de amigos, críticas de livros, filmes e músicas, ou guias de restaurantes e viagens. Resnick and Varian (1997) mostram que os sistemas de recomendações apoiam e aumentam esse processo natural. Basicamente, o que temos aqui são técnicas e ferramentas de programas para fornecer sugestões de itens que sejam úteis para um usuário. Nesses sistemas, "item" é um termo genérico utilizado para denotar o que o sistema oferece a um usuário (Ricci et al., 2011), neste trabalho um "item" é uma música.

\subsection{Conceitos e Tarefas}

Os sistemas de recomendação utilizam basicamente três tipos de dados para suprir seu objetivo: itens, usuários e relações dos usuários com os itens (Ricci et al., 2011).

- Itens: São os objetos recomendados. Podem ser caracterizados por sua complexidade e por seu valor ou utilidade. $\mathrm{O}$ valor deste pode ser positivo se o item é útil para o usuário, ou negativo se o item é inapropriado e o usuário tomou uma decisão errada ao selecioná-lo. Itens podem ser representados utilizando várias abordagens de representação e informação. Por exemplo, o filme é o item a ser recomendado no Netflix e a faixa no Spotify.

- Usuários: Podem ter diversos objetivos e características. Para personalizar as recomendações, os sistemas de recomendação exploram um conjunto de informações sobre o usuário. Essas informações podem ser estruturadas de várias maneiras, e a seleção de quais informações modelar depende da técnica de recomendação. Usuários também podem ser descritos pelos seus padrões de comportamento, como dados de navegação em um site.

- Transações: Transações são registros de interação entre o usuário e o sistema de recomendação. São como dados de log que armazenam informações importantes geradas durante a interação humano- computador, os quais serão usadas pelos algoritmos de recomendação do sistema para encontrar recomendações úteis aos usuários.

\subsection{Técnicas de Recomendação}

Para encontrar as recomendações que serão colocadas em forma de lista ranqueada, são utilizadas algumas técnicas, feitas a partir da predição sobre as informações dos itens e usuários.

Várias foram as técnicas propostas como base para um sistema de recomendação, como as técnicas colaborativa, baseada em conteúdo, baseada em conhecimento, demográfica, social e grupal. As técnicas de recomendação podem ser diferenciadas com base em suas fontes de dados: de onde vêm os dados necessários para encontrar as recomendações? Em alguns sistemas, esses dados são as preferências de outros usuários (Burke, 2007). Em outros sistemas, esses dados são as descrições que compõem o "item".

A utilidade de um item para um usuário pode ser influenciada pelo conhecimento que este tem do domínio - por exemplo, usuários iniciantes versus experientes de uma câmera digital - ou pode depender do momento (local ou hora) em que a recomendação foi feita. Ou suponhamos que o interesse maior seja por itens mais perto de seu localização - um restaurante ou local turístico por exemplo. Assim, o sistema de recomendação deve se adaptar para que esses detalhes específicos possam ser usados no momento de encontrar as recomendações (Ricci et al., 2011).

\subsection{Filtragem Colaborativa}

Na filtragem colaborativa, o sistema recomenda ao usuário ativo itens que outros perfis com gostos semelhantes consumiram no passado. A semelhança de gostos de dois usuários é calculada baseada na similaridade do histórico de classificações de ambos. A filtragem colaborativa é considerada a técnica em sistemas de recomendação mais popular e mais largamente implementada (Ricci et al., 2011).

A ideia chave é que a classificação de um usuário $u$ para um novo item $i$ é provável de ser similar com a de outro usuário $v$, se $u$ e $v$ têm classificado outros itens de maneira similar. De mesmo modo, é provável que $u$ classifique dois itens $i$ e $j$ de forma semelhante, se outros perfis têm feito classificações aproximadas para estes dois itens (Ricci et al., 2011).

Em Burke (2002, 2007), tem-se que os métodos de filtragem colaborativa podem ser divididos nas duas classes gerais: baseados em vizinhança e modelo. $\mathrm{Na}$ filtragem colaborativa baseada em vizinhança, as classificações usuário-item armazenadas no sistema são utilizadas diretamente para predizer classificações de novos itens. Isto pode ser feito de duas maneiras conhecidas: se baseada no usuário ou no item (Ricci et al., 2011). Já a que se baseia em modelo usa os dados do histórico do usuário para predizer os itens que lhe serão relevantes. 


\subsubsection{Problemas e Limitações}

A filtragem colaborativa possui alguns problemas que a comunidade cientifica vem tentando resolver, entre estas estão: partida a frio, dado esparso e o enviesamento por popularidade (Celma, 2010, Qin, 2013, Isinkaye et al., 2015).

- Partida a frio: É a dificuldade de encontrar usuários ou itens similares, devido a falta de informação sobre as transações do usuário. O problema de partida a frio é um dos principais problemas de sistemas de recomendação e sua implicação é redução da precisão. Sistemas colaborativos não podem recomendar novos itens até que os usuários forneçam dados sobre suas preferências.

- Dado esparso: Este problema diz a respeito da esparsidade encontrada nas matrizes item-usuário, este problema acontece em decorrência da falta de retorno dos usuários, assim apenas uma pequena parte dos itens são classificados pelos usuários na base de dados. Matriz esparsa é comum em sistemas de recomendação. Menos de $0,1 \%$ dos itens são classificados pelo usuário (Celma, 2010).

- Enviesamento por popularidade: Este problema é comum em sistemas colaborativos. Uma analogia comum a este problema é o ditado "ricos ficam ricos" (Celma, 2010). O enviesamento acontece ao recomendar itens mais conhecidos pelos usuários descartando assim os menos conhecidos.

\subsubsection{Vantagens}

A filtragem colaborativa possui algumas vantagens.

- Alguns algoritmos baseados em memória são fáceis de implementar e manter, provendo resultados concisos e com justificativa intuitiva (Ricci et al., 2011).

- Filtragem colaborativa funciona bem em ambientes com escassez de informação sobre os itens (Isinkaye et al., 2015).

- Métodos baseados em modelos têm uma melhor precisão na sugestão (B.Thorat et al., 2015).

\subsection{Filtragem Baseada em Conteúdo}

De acordo com Adomavicius and Tuzhilin (2005), o método baseado em conteúdo tem sua origem nas pesquisas de recuperação da informação. Sistemas de recomendação baseados em conteúdo indicam itens similares a àqueles que um usuário preferiu no passado, ao passo que sistemas que implementaram a técnica de recomendação colaborativa identificam usuários que possuem preferências similares a outros e sugerem itens que eles têm preferido (Lops et al., 2011).

Sistemas que implementam uma abordagem de recomendação baseada em conteúdo analisam um conjunto de descrições dos itens previamente classificados pelo usuário $u$, para assim construir um perfil ou modelo de interesses do usuário baseado nas características dos itens classificados (Mladenic, 1999). O modelo é uma representação estruturada das preferências do usuário, adaptado para encontrar e recomendar novos itens que possam ser de seu interesse. O processo de recomendação consiste em comparar os atributos do modelo do usuário com os atributos de um item. O resultado é um julgamento de relevância que representa os níveis de interesse do usuário naquele item. Se um modelo reflete com precisão as preferências do usuário, isso é uma grande vantagem para a eficácia no processo de recomendação (Lops et al., 2011).

\subsubsection{Extração de Atributos}

Sistemas de recomendação de música encontram a similaridade entre as músicas e usam as informações para sugerir novas músicas. Celma (2010) apresenta duas formas de analisar os conteúdos das músicas: automática ou manualmente.

- Automática: Geralmente, no processo automático de extração das características, o áudio é semanticamente anotado para que então a similaridade entre as músicas seja computada. Depois disso, músicas são recomendadas se "soarem" de forma semelhante às músicas no modelo do usuário.

- Manual: Em relação à extração manual, apesar de ser considerada muito demorada, devido à entrada de dados ser dependente de humanos, pode ser ainda mais precisa do que o processo automático.

O conteúdo das músicas podem ser representados através de detecção de atributo de áudio, metadados, ou análise de representação simbólica. Pachet (2003) e Qin (2013) apresentam três formas de analisar os dados:

- Metadado Editorial: Referente às informações do álbum, tais como: artista, nome do álbum, nome da música, ano, gênero e relações entre os artistas. Estas informações são providas de anotação manual dos dados e normalmente são cedidas por um editor, autoridades no assunto ou grupo de especialistas.

- Metadado Acústico: É obtido através da análise direta dos arquivos de áudio sem nenhuma outra referência. Este metadado inclui atributos de sinais de baixo nível e conceitos musicais de alto nível. Os atributos de baixo nível são categorizados em atributos temporais ou atributos espectrais. Os conceitos de alto nível englobam informações como: timbre, melodia, ritmo e a estrutura musical.

- Metadado Cultural: Dados extraídos da Internet (weblogs e fóruns), o conteúdo é relacionado com a música. Metadado cultural é resultado de análise de padrões, categorias ou associações providas pela fonte.

\subsubsection{Problemas e Limitações}

A filtragem baseada em conteúdo possui alguns problemas que a comunidade cientifica vem tentando resolver, entre estas estão: superespecialização, partida a frio e escassez de dados.

- Superespecialização: É um problema sobre encontrar músicas muito similares com as do usuário, dificultando a novidade, diversidade e surpresa para 0 usuário. Lops et al. (2011) argumentam que sistemas baseados em conteúdo não possuem a habilidade de 
encontrar algo inesperado para o usuário.

- Partida a frio: Um novo usuário do sistema não possui músicas classificadas ainda, assim o sistema de recomendação baseado em conteúdo demora para entender o gosto do usuário e prover músicas similares.

- Escassez de dados: Este problema é um dos principais em aprendizado de máquina e mineração de dados, devido à pequena quantidade de informação sobre o item se torna difícil realizar aprendizado e inferir algo. Sistemas de recomendação baseados em conteúdo sofrem com escassez de informação devido à pouca descrição dos itens da base de dados, impactando negativamente na precisão do sistema. Este problema é diferente do problema de esparsidade nos dados, sendo que a esparsidade são dados faltantes em alguns itens e a escassez de dados é a não existência desses dados em nenhum dos itens. A escassez de dados também se diferencia da partida a frio, devido a este problema aplicado aos usuários que acabaram de entrar no sistema ou não dão retorno durante seu uso.

\subsubsection{Vantagens}

A filtragem baseada em conteúdo possui algumas vantagens.

- Provê uma fácil explicação de como as recomendações acontecem para cada usuário.

- Mesmo com o problema da partida a frio esta técnica tem a habilidade de recomendar.

- As classificações que um usuário ajudam a criar um perfil único e personalizado, ajustando-se em um pequeno espaço de tempo aos novos itens que o usuário inseriu em suas preferências.

\section{Trabalhos Relacionados}

Na Seção 2 apresentamos os principais conceitos de sistemas de recomendação e algumas definições próprias da aplicação com música. A partir disto podemos definir com melhor detalhes a nossa pesquisa. Neste artigo apresentamos um sistema de recomendação de música baseado em conteúdo que encontra uma lista de sugestões personalizada em um ambiente com escassez de informação e fazendo-se uso dos metadados editoriais da música para encontrar a similaridade.

Bogdanov and Herrera (2011) apresentam um sistema de recomendação baseado em conteúdo que utiliza dos metadados acústicos e editoriais para encontrar a lista de recomendação. O estudo busca entender a quantidade de atributos para encontrar a lista. Os metadados utilizados no trabalho são: timbre, tempo, tom, título, artista, álbum e gênero. $\mathrm{O}$ estudo deles se difere do nosso na quantidade e nos metadados utilizados. Nossa proposta é utilizar somente metadados editoriais e entender se é possível recomendar música com um ou mais metadados.

Logan (2004) explora o problema da recomendação de música baseada exclusivamente na frequência do áudio (metadado acústico), onde o áudio é convertido em Mel-Frequency Cepstral Coefficients - (MFCCs), que per- mite assim capturar informações espectrais suavizadas que correspondem aproximadamente a instrumentação e timbres. Em seu trabalho, ele também propõe soluções que podem ser usadas com qualquer medida de similaridade baseada em acústica: a mediana, a média e a distância mínima da similaridade entre uma música e um conjunto de músicas.

Hijikata et al. (2006) propõem um sistema de filtragem baseado em conteúdo, usando uma árvore de decisão. Eles utilizam diversos dados contidos na extensão de áudio Musical Instrument Digital Interface - (MIDI), como: tempo, tonalidade, ritmo, tom, metro, pitch e a diferença de duração.

Knees et al. (2006) apresentam uma técnica para combinar a semelhança musical do sinal de áudio com semelhança musical do artista, baseado na web para acelerar a tarefa de geração automática de listas de reprodução. Eles exploram a similaridade determinada automaticamente por meio de recuperação da Web para evitar o cálculo de similaridade entre as faixas de diferentes artistas e/ou não relacionados.

Desde 2005, a comunidade de pesquisa ampliou sua atenção para incluir outros aspectos, como abordagem híbrida. Yoshii et al. (2006) apresentaram um método de recomendação de música hibrido que resolve problemas de dois métodos convencionais proeminentes: filtragem colaborativa e recomendação baseada em conteúdo. O método usado integra dados de classificação e conteúdo, usando uma rede Bayesiana chamada modelo de aspecto. Yoshii and Goto (2009) apresentaram uma indexação semântica latente probabilística (pLSI), que lida com dados de classificação fornecidos pelo usuários e outros extraídos de sinais de áudio. Tiemann and Pauws (2007) investigaram os métodos de aprendizagem de conjunto (Ensemble Learning), combinando uma abordagem social e algoritmos de recomendação baseados em conteúdo.

Flexer et al. (n.d.) apresentam um sistema gerador de listas de reprodução com base em uma música de início e fim, criando uma transição suave que permite aos usuários descobrirem novas músicas em uma coleção. A abordagem utilizada é baseada na similaridade dos atributos de áudio MFCCs e não requer nenhum tipo de metadado manualmente extraído. Fields (2011) apresenta em seu trabalho um sistema que utiliza metadados das redes sociais e os atributos do áudio para criar uma lista de reprodução personalizada. Pampalk et al. (2005) apresentam um sistema que adapta automaticamente as listas de reprodução, a partir de uma música inicial e feedback imediato do usuário. Os atributos de áudio foram utilizados para encontrar a similaridade entre as músicas. $\mathrm{O}$ usuário dá o feedback pressionando o botão "pular" caso não goste da música atual. Músicas semelhantes às ignoradas são removidas, enquanto as que se assemelhem às não ignoradas são adicionadas à lista de reprodução.

Nakamura et al. (2017) extraem das letras das músicas todas as palavras que podem ser utilizadas para descrever a música e então usam para formar um grafo. Alguns trabalhos como os de Wang et al. (2018) utilizam tags das músicas para encontrar as recomendações. Em sua pesquisa Wang et al. (2018) desenvolve um sistema 
de recomendação que se baseia em filtragem colaborativa, mas utiliza as tags para guiar as recomendações.

Os trabalhos apresentados nos mostram a importância deste trabalho que busca saber se em um ambiente com escassez de informação é possível recomendar músicas com um ou mais atributos, além do uso de apenas metadados editoriais. Para isto, um modelo de recomendação que seja adequado para a situação se torna necessário.

\section{Recomendação de Música por Similari- dade}

Nesta seção é abordada a solução proposta: um sistema de recomendação de música baseado em conteúdo com recomendações personalizadas, baseadas nas preferências dos usuários, utilizando os metadados editoriais das músicas. Além de explicitar o processo de construção, as formulações e os modelos dos dados usados.

\subsection{Algoritmos}

\subsubsection{Medidas de similaridade baseada em conteúdo}

Neste trabalho, utilizamos como entrada de dados das música o metadado editorial, ou seja, dados textuais disponibilizados por algum conjunto de dados público. Assim, o sistema proposto pode encontrar a similaridade entre os metadados, calculando o cosseno entre os dados usando o TF-IDF para compor o modelo vetorial.

\subsubsection{TF-IDF}

O Term Frequency-Inverse Document Frequency (TF-IDF), que significa frequência do termo-inverso da frequência nos documentos, é uma medida estatística que tem o intuito de indicar a importância de uma palavra de um documento, em relação a uma coleção de documentos, ou em um corpus linguístico. $\mathrm{O}$ valor TF de uma palavra aumenta proporcionalmente à medida que aumenta o número de ocorrências dela em um documento. Esse valor, no entanto, é equilibrado pela frequência da palavra no corpus IDF. Isso auxilia a distinguir o fato da ocorrência de algumas palavras serem geralmente mais comuns que outras.

Na Eq. (1), o TF é dado como $n_{t}$ que é o número de vezes em que o termo $t$ aparece no documento $m$ dividido por $n_{m}$, que é o número total de termos no documento $m$. O IDF, na Eq. (2), trabalha como um ajuste no TF, visto que alguns termos ocorrem mais que outros. Assim, na equação, $n_{M}$ é dado como o número total de documentos pertencentes ao conjunto $M$, dividido por $n_{M t}$, que é o número de documentos pertencentes ao conjunto $M$ que contenha o termo $t$. $O$ 1 adicionado no denominador previne a divisão por 0 , o 1 adicionado no dividendo garante que o valor seja maior ou igual a 1, o terceiro 1 garante que o valor seja maior que 0. Assim, na Eq. (3), temos a multiplicação do TF pelo IDF.

$$
\operatorname{TF}(t, m)=\frac{n_{t}}{n_{m}}
$$

$$
\begin{gathered}
\operatorname{IDF}(t, M)=\log \left(\frac{n_{M}+1}{n_{M t}+1}+1\right) \\
\operatorname{TFIDF}(t, m, M)=\frac{n_{t}}{n_{m}} \times \log \left(\frac{n_{M}+1}{n_{M t}+1}+1\right)
\end{gathered}
$$

Por exemplo, sendo o corpus $M$ composto pelos documentos: "Rock It", "Easily", "Evil Deeds", "Rock a My Soul", "Easily", "Rock The BeaT", "Music My Rock", "Robot Rock". Cada documento é processado pela biblioteca NLTK para a retirada de "palavras vazias" (stop word), vetorização, e identificação dos termos: "beat": o, "deed": 1, "easily": 2 , "evil": 3, , "music": 4, "robot": 5, "rock": 6 , "soul": 7. Palavras como: "it", "a", "my", "the", são retiradas durante o preprocessamento por serem palavras vazias. Sabendo-se agora quais são os termos do corpus $M$, torna-se viável realizar uma contagem dos termos em todos os documentos.

\subsubsection{Similaridade do Cossenos}

A similaridade entre cossenos é uma métrica estatística, usada em sistemas de recomendação nos campos textuais, para medir a similaridade entre os documentos. Levando em consideração um modelo de espaço vetorial e calculando o ângulo $\theta$ entre dois documentos $\vec{A}$ e $\vec{B}$ (Singhal and Google, 2001). Sendo o valor gerado da similaridade entre 0.0 e 1.0: o primeiro indica que os vetores são ortogonais entre si, enquanto o último indica que os vetores são idênticos. A Eq. (4) é uma representação formal de como a similaridade é encontrada. Neste trabalho, o modelo de espaço vetorial é preparado pelo TF-IDF.

$$
\cos (A, B)=\frac{\sum_{i=1}^{n} A_{i} \cdot B_{i}}{\sqrt{\sum_{i=1}^{n} A_{i}^{2}} \cdot \sqrt{\sum_{i=1}^{n} B_{i}^{2}}}
$$

\subsection{Modelagem dos dados}

Os dados usados no sistema são formalmente modelados, especificados e seus domínios definidos nesta subseção.

\subsubsection{Modelo do Usuário}

O conjunto dos usuários $U=\left\{u 1, \ldots, u n / 1 \leqslant n \leqslant N^{*}\right\}$ é formado por todos os usuários que podem receber recomendações do sistema. Assim, o usuário $u \in U$ é representado unicamente por uma identificação, que é um valor único no sistema $\langle U I D\rangle$. O modelo do usuário $M U_{u}$ é a representação de todas as músicas que o usuário adicionou nas preferências, como é possível visualizar na Fig. 1b.

\subsubsection{Item de Recomendação: Música}

O conjunto das músicas $M=\left\{m 1, \ldots, m n / 1 \leqslant n \leqslant N^{*}\right\}$ é formado por todas as músicas que podem ser recomendadas. Assim para analisar os metadados das faixas e 


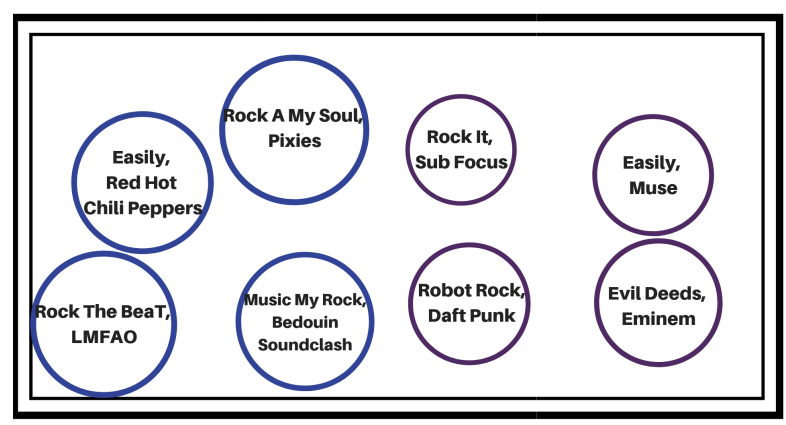

(a)

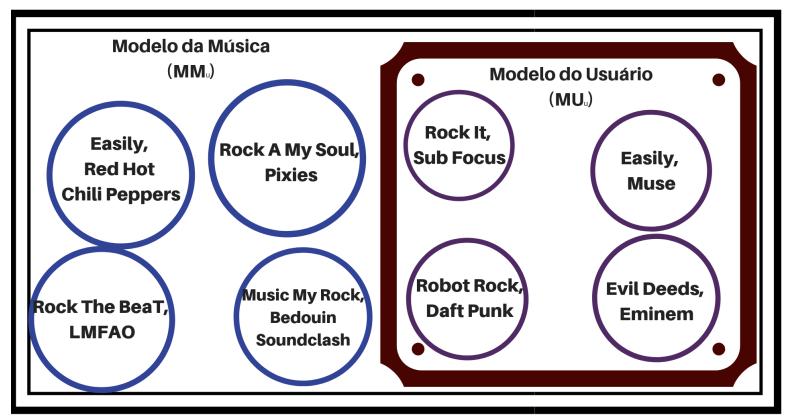

(c)

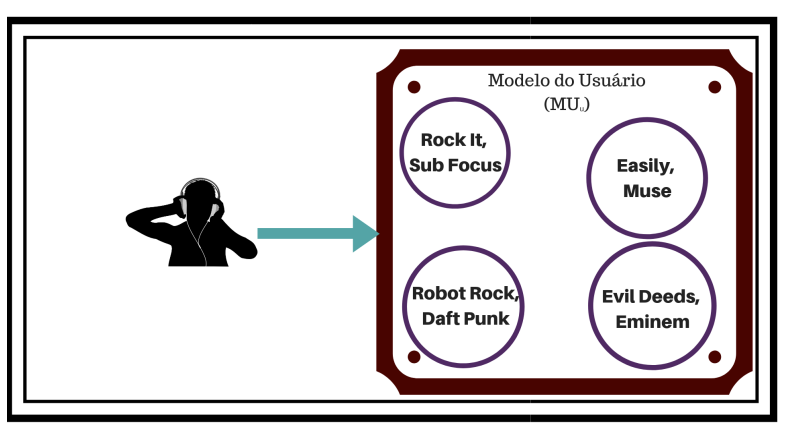

(b)

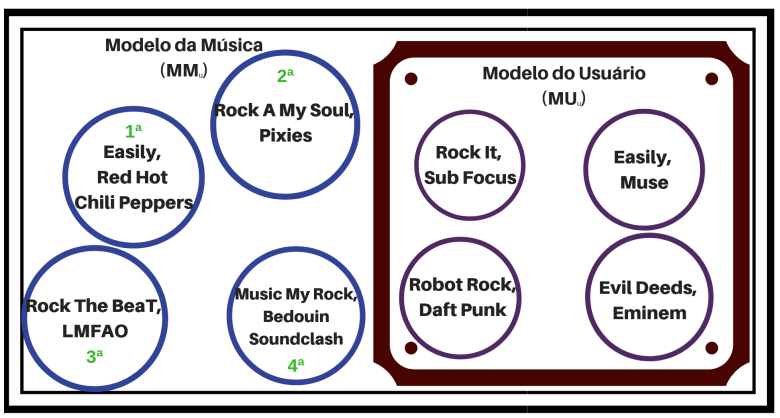

(d)

Figura 1: Representando (a) conjunto de músicas, (b) modelo do usuário, (c) modelo de músicas e o modelo do usuário, e (d) modelo de recomendação.

fazer um bom uso deles durante a recomendação, formalmente cada música $m \in M$ é representada como um conjunto de metadados distinguidas em uma quádrupla $\langle U I D, T L, A L, A R\rangle$, que significa da esquerda pra direita as informações sobre a música: UID é a identificação única daquela canção, TL é o metadado textual que representa o Título da faixa, $A L$ é o metadado textual que representa o Álbum ao qual esta pertence e $A R$ é o metadado textual que representa o Artista ou Banda intérprete. $\mathrm{O}$ modelo da música $M M_{u}=M-M U_{u}$ é formado por todas as músicas ainda não adicionadas nas preferências do usuário $u$. A Fig. 1a representa todo o conjunto de músicas disponíveis; a Fig. 1c representa na esquerda o modelo de músicas e na direita o modelo do usuário.

\subsection{Modelo de Recomendação}

A similaridade entre uma música $m$ e um modelo do usuário $M U_{u}$ é dada através de um cálculo que realiza a soma dos valores das similaridades de $m$ com cada canção $m \in M U_{u}$. Por fim, realiza uma divisão pelo número de obras similares $Q_{m}$. Uma música é similar se possui o valor de $\cos \left(M U_{u}(A), m\right)$ maior que zero. Este cálculo é formalmente apresentado na Eq. (5).

$$
S\left(M U_{u}, m\right)=\frac{\sum_{A=1}^{\left|M U_{u}\right|} \cos \left(M U_{u}(A), m\right)}{Q_{m}}
$$

Na Tabela 1, por exemplo, é possível verificar que a faixa "Rock a My Soul" tem similaridade com duas outras, do modelo desse usuário: "Rock It" com similaridade 0.489 e "Robot Rock" com similaridade 0.239 . Assim, somando a similaridade e dividindo por duas ocorrências temos a média do valor 0.364 . Neste exemplo utilizamos a similaridade entre os títulos das músicas, entretanto na Seção 5.1 iremos definir a metodologia de uso dos metadados.

O modelo de recomendação visa sugerir novas músicas que os usuários não conheçam, vindo assim a serem adicionadas como preferidas. A Eq. (6) é uma definição formal deste. Para cada usuário $u \in U$, o sistema deseja recomendar músicas desconhecidas $\left(m^{\max , u} \in M M_{u}\right)$ que sejam maximizadas pela função recModel, descrita na Eq. (7). $O$ arg $\max _{m \in M M_{u}}$ ranqueia de forma decrescente os resultados providos do cálculo médio do interesse do usuário sobre as músicas, criando assim a lista de recomendação para cada usuário.

$$
\forall u \in U, m^{\max , u}=\arg \max _{m \in M M_{u}} \operatorname{recModel}(u, m)
$$

Onde o modelo das músicas $M M_{u}$ é composto por músicas não conhecidas pelo usuário $u \in U$. E o recModel é a função de similaridade entre o modelo do usuário $M U_{u}$ e uma música $m \in M M_{u}$, assim como descrito na Eq. (7). 


\begin{tabular}{|c|c|c|c|c|c|}
\hline & Rock It & Easily & Evil Deeds & Robot Rock & média \\
\hline Rock a My Soul & 0.489 & 0.0 & 0.0 & 0.239 & 0.364 \\
\hline
\end{tabular}

Tabela 1: Similaridade da música "Rock a My Soul" com o $M M_{u}$ sendo duas músicas similares.

\begin{tabular}{|l|c|c|c|c|}
\cline { 2 - 5 } \multicolumn{1}{c|}{} & Rock It & Easily & Evil Deeds & Robot Rock \\
\hline Easily & 0.0 & 1.0 & 0.0 & 0.0 \\
\hline Rock a My Soul & 0.489 & 0.0 & 0.0 & 0.239 \\
\hline Rock the BeaT & 0.489 & 0.0 & 0.0 & 0.239 \\
\hline Music My Rock & 0.489 & 0.0 & 0.0 & 0.239 \\
\hline
\end{tabular}

\begin{tabular}{|c|}
\hline Similaridade \\
\hline 1.0 \\
\hline 0.364 \\
\hline 0.364 \\
\hline 0.364 \\
\hline
\end{tabular}

$$
\operatorname{recModel}(u, m)=S\left(M U_{u}, m\right)
$$

É possível observar, por exemplo, na Tabela 2 as composições que seriam sugeridas pelo modelo de recomendação.

\section{Avaliação}

Nesta seção, é mostrado o processo de avaliação utilizado para verificar se os objetivos previstos foram alcançados. Também apresenta os detalhes da metodologia utilizada para desenvolver e avaliar este trabalho, bem como o conjunto de dados utilizados durante os experimentos. Em seguida, são apresentadas as métricas utilizadas na avaliação.

\subsection{Metodologia}

Os experimentos realizados têm por objetivo mostrar que é possível recomendar canções em um cenário com escassez de informação e qual a melhor forma de utilizar os metadados. Abaixo estão descritos os três experimentos realizados compostos de três testes variando a composição dos metadados:

i. Experimentos Tipo 1: Este é composto de testes do sistema realizados de forma isolada para encontrar assim as recomendações. 0 experimento realiza o uso de 3 metadados: MT1, MT2 e MT3. Primeiramente, é utilizado o metadado MT1 para encontrar as recomendações, depois o MT2 é usado de forma isolada para encontrar as sugestões e, por fim, o metadado $M T 3$ é usado separadamente também. Nos resultados, estes experimentos são representados pelo nome do metadado.

ii. Experimentos Tipo 2: A média da similaridade de dois metadados é utilizada para encontrar as recomendações. Usamos os atributos MT1 e o MT2 de duas músicas para encontrar a similaridade entre cada atributo e depois realizamos a média. A similaridade do $M T 1$ da música $A$ com o $M T 1$ da música $B$ mais a similaridade do $M T 2$ da música $A$ com o MT2 da música $B$, dividido por 2. Nos resultados, estes experimentos são representados com os nomes dos dois metadados utilizando o simbolo de módulo
$|M T 1|+|M T 2|$.

iii. Experimentos Tipo 3: Neste experimento concatenamos dois atributos de uma música transformando-os em apenas um atributos para assim realizar o cálculo da similaridade. Por exemplo, o MT1 e o MT2 da música A são concatenados em $M T 1+M T 2$, e o $M T 1$ e o $M T 2$ da música $B$ também são concatenados da mesma forma, para assim serem usados como um único atributo na hora de encontrar a similaridade entre a música $A$ e a música $B$. Nos resultados, estes experimentos são representados com os nomes dos dois metadados sem o símbolo de módulo MT1 + MT2.

Para avaliar os experimentos no sistema proposto e seu modelo de recomendação são utilizados três metadados: Título, Álbum e Artista. As listas de sugestões encontradas em cada experimento são avaliadas em 5 tamanhos: 1, 5, 10, 15 e 20 músicas recomendadas. O conjunto de composições relevantes ou esperadas a serem propostas aos usuários é determinado pelo desvio padrão das vezes em que a música foi adicionada nas preferências dos usuários. Para avaliar os resultados, 6 amostragens são realizadas, das quais 3 com 1000 usuários e variações de 3000,6000 e 9000 músicas. E os outros 3 testes são com 10000 canções e variações de 100, 500 e 1000 usuários.

\subsection{Conjunto de dados}

O One Million Song Dataset - (OMS) (Mahieux et al., 2011, McFee et al., 2012) é uma coleção grátis de informações de áudio e metadados para um milhão de faixas musicais. O dataset contém: 1.000 .000 de músicas e arquivos, 44.745 artistas, 2.321 tags. Ele traz de cada canção um total de 55 campos de dados, como: título, ano, artista, letra, andamento, timbre, duração e etc. Conjuntos menores de dados com menos campos também são disponibilizados. Além das informações sobre as músicas o OMS possui diversos dados complementares como um dataset com as preferências dos usuários sobre as músicas. Assim para a avaliação são utilizados os metadados da música e as preferências do usuário providos pelo OMS.

Na Tabela 3 encontra-se o levantamento dos dados utilizados com 10000 músicas e 76353 usuários. Os valores da média, mediana e desvio padrão representam o número de vezes que uma canção é adicionada nas 


\begin{tabular}{|l|c|c|c|c|c|c|}
\cline { 2 - 7 } \multicolumn{1}{c|}{} & Total & Média & Mediana & Desvio Padrão & Maior que o DP & Menor que DP \\
\hline Músicas & 10000 & 200 & 124 & 317 & 1157 & 8843 \\
\hline Usuários & 76353 & 26 & 16 & 31 & 18793 & 57560 \\
\hline
\end{tabular}

Tabela 3: Informações sobre o conjunto de dados usado.

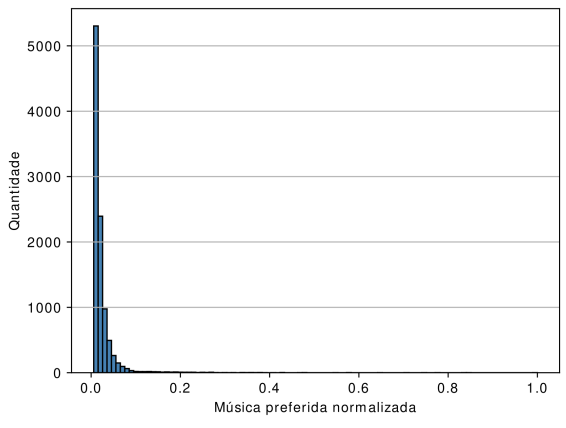

(a) Músicas.

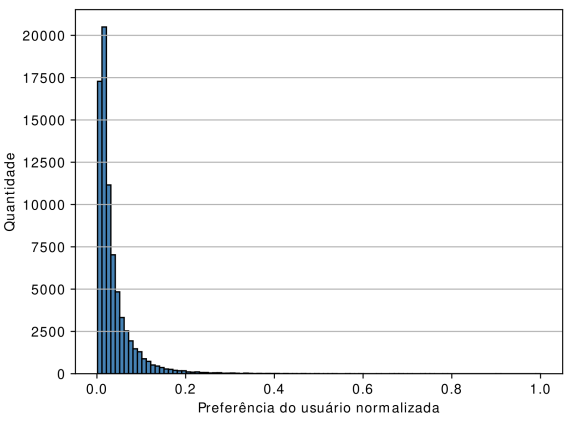

(b) Usuários.

Figura 2: Histogramas normalizados.

preferências dos usuários. Para este trabalho foram utilizadas 2 milhões de preferências.

Para os dados da Tabela 3, contamos quantas vezes as músicas aparecem nos modelos dos usuários, com este valor calculamos cada coluna da tabela. O uso do Desvio Padrão - (DP) é uma decisão de projeto. A coluna "Maior que o DP", representa a quantidade de obras que fazem parte do conjunto de músicas esperadas a constituírem as listas de sugestões com 1157 e de usuários para encontrar recomendações com 18793. A coluna "Menor que o DP", representa o oposto, ou seja, as músicas não esperadas na constituição das listas de recomendações, com 8843 músicas e 57560 usuários com poucas músicas adicionadas a preferências. Com essa análise, criamos um cenário no qual $11 \%$ das músicas são consideradas relevantes e que, portanto, nos habilita a realizar o cálculo das métricas, permitindo que esta avaliação seja realizada de forma estratificada.

No histograma normalizado da Fig. 2a é possível verificar a distribuição das composiçõ̃es. O valor de normalização é dado pela música que foi mais adicionada nas preferências dos usuários, sendo 8277 o total de usuários que a adicionaram e 0,038 o desvio padrão normalizado. No histograma da Fig. $2 \mathrm{~b}$ é possível visualizar a distribuição dos usuários, sendo o valor de normalização dado pelo perfil que mais adicionou canções em sua lista de preferência, com um valor de 711 e o desvio padrão normalizado de 0,044. Assim, é possível obter as músicas que farão parte do conjunto de músicas esperadas e também é possível obter os usuários mais ativos para encontrar indicações.

\subsection{Métricas de Avaliação}

Existem diversas métricas que podem ser utilizadas para avaliar a qualidade do ranque de um sistema de recomendação. Neste trabalho, são utilizadas duas mé- tricas, uma para precisão e outra para reciprocidade. Assim, é considerado um acerto quando a música recomendada faz parte das 1157 "Maior que o DP", caso contrario é considerado como uma sugestão errada. Caso a lista de recomendação não possua nenhuma canção que faça parte do conjunto de músicas esperadas, o valor do resultado é zero.

\subsubsection{Mean Average Precision - MAP}

A fim de obter uma métrica única que contribui para a precisão do método de recomendação ao longo de todo o conjunto de usuários, utiliza-se o MAP (Parra and Sahebi, 2013). O valor do MAP é obtido calculando a média sobre a precisão média da lista de recomendações de cada usuário.

$$
\begin{gathered}
M A P=\frac{1}{|U|} \sum_{u}^{U} \operatorname{AveP}(u) \\
\operatorname{AveP}(u)=\frac{1}{N} \sum_{i=1}^{N} p @ i \\
p @ i=\frac{r}{i}
\end{gathered}
$$

Na Eq. (8), AveP(u) é a média da precisão para o usuário $u \in U$, isto é, a média dos valores da precisão obtidos para o conjunto de top- $\mathrm{N}$ recomendações depois que cada sugestão relevante é recuperada (Manning et al., 2008). As Eqs. (9) e (10) mostra o cálculo da média da precisão, que é uma soma da precisão em cada posição da lista $p @ i$ onde $r$ é a quantidade de músicas relevantes até a posição $i$. 


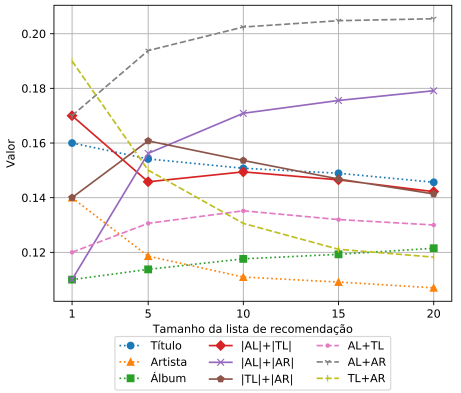

(a) 100 Usuários

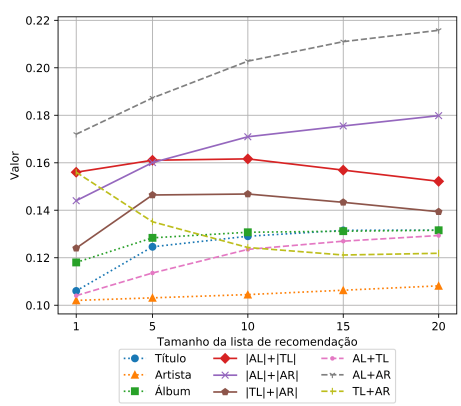

(b) 500 Usuários

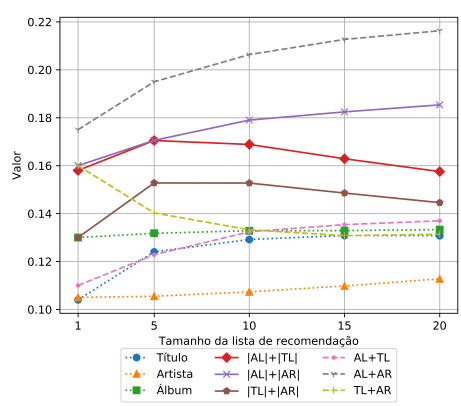

(c) 1000 Usuários

Figura 3: MAP - Gráfico com linhas dos experimentos com 10000 músicas e três variações no número de usuários: 100, 500 e 1000 .

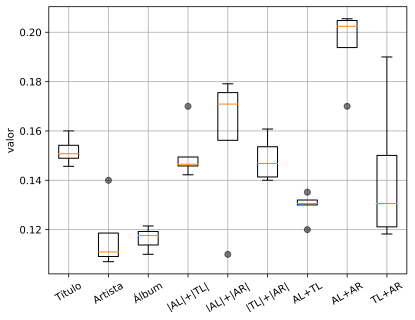

(a) 100 Usuários

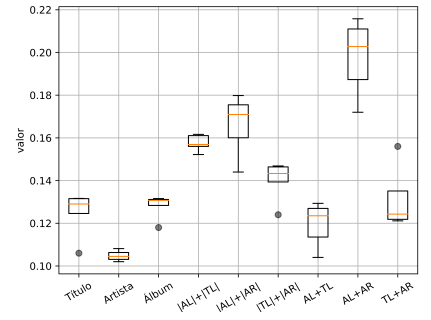

(b) 500 Usuários

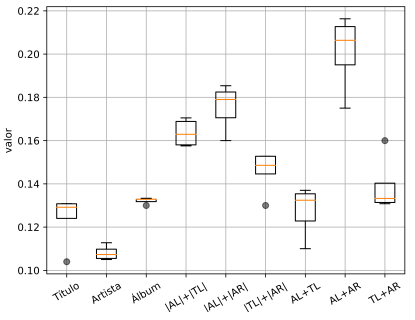

(c) 1000 Usuários

Figura 4: MAP - Gráfico com caixas dos experimentos com 10000 músicas e três variações no número de usuários: 100, 500 e 1000.

\subsubsection{Mean Reciprocal Rank - MRR}

$\mathrm{O} M R R$ avalia a qualidade das listas de recomendação na posição top-N, medindo o quão longe o primeiro item relevante está do topo da lista (Qin, 2013). É definido como:

$$
M R R=\frac{1}{|U|} \sum_{u}^{U} \frac{1}{p_{i}}
$$

Na Eq. (11) é possível verificar a formulação do $M R R$ onde $\forall u \in U$ a primeira ocorrência de uma recomendação relevante $p_{i}$ é avaliada.

\section{Resultados}

Espera-se que em um cenário com escassez de metadados o sistema proposto consiga recomendar novas composições aos usuários, de forma personalizada.

\subsection{MAP}

\subsubsection{Amostragem do usuário}

A métrica MAP é utilizada para medir a precisão do sistema perante todos os seus usuários e aplicada em todos os experimentos. Nas Figs. 3 a 6 encontram-se os resultados dos testes. Dentre os seis testes reali- zados, a combinação dos metadados $A L+A R$ (Álbum e Artista) pertencente ao Experimento 3 obteve cinco dos melhores resultados. Assim como o metadado Artista, que trabalhado de forma isolada, obtém todos os piores resultados no sistema proposto.

Os testes realizados com 10000 composições e as variações no número de usuários apresentam, nas Figs. 3 e 4, que, no sistema proposto, os Experimentos 2 e 3 obtêm os melhores resultados. Também é possível visualizar, na Fig. 3, que quanto maior a lista de recomendação os resultados sofrem variações. O Experimento 1 em todos os testes obtém os piores resultados, sendo o metadado Artista o com a pior precisão a ser trabalhado de forma isolada. O Experimento 2 obtém bons resultados quando se olha para todas as médias da similaridade dos metadados. O Experimento 3, no sistema proposto, obtém melhores resultados com a concatenação dos metadados $A L+A R$ (Álbum e Artista), entretanto, as outras concatenações de metadados deste experimento obtêm resultados menores do que as do Experimento 2. A Fig. 4 ressalta em sua análise que todos os experimentos obtêm outliers, sendo a maioria com um outlier e unicamente a concatenação dos metadados $A L+T L$ (Álbum e Título) da Fig. 4a obtém dois outliers. Com exceção dos outliers, a variação dos resultados é pequena, exceto o $\mathrm{TL}+\mathrm{AR}$ (Título e Artista) na Fig. 4a. 


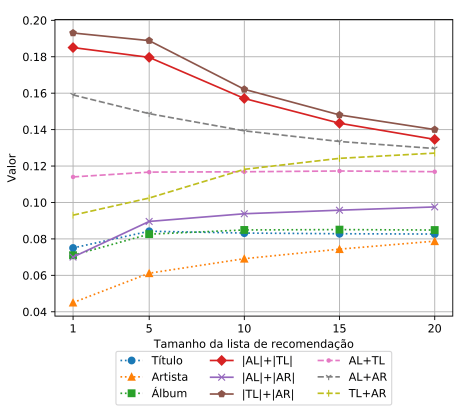

(a) 3000 Músicas

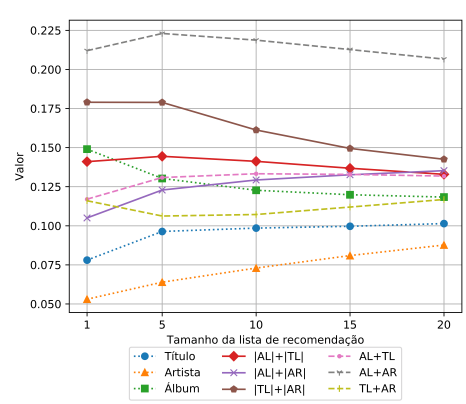

(b) 6000 Músicas

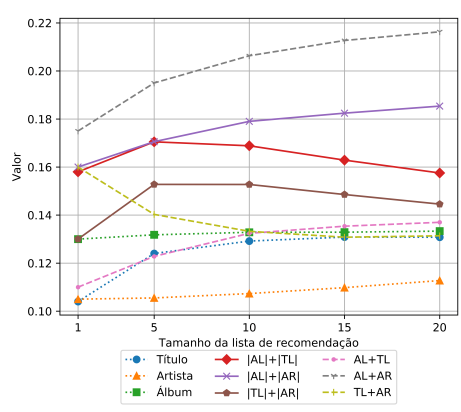

(c) 9000 Músicas

Figura 5: MAP - Gráfico com linhas dos experimentos com 1000 usuários e três variações no número de músicas: 3000,6000 e 9000 .

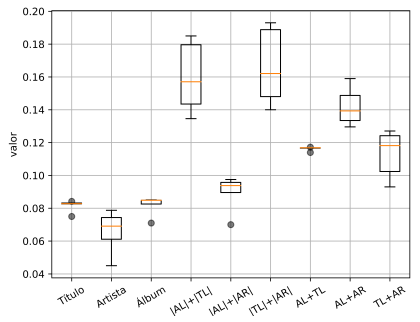

(a) 3000 Músicas

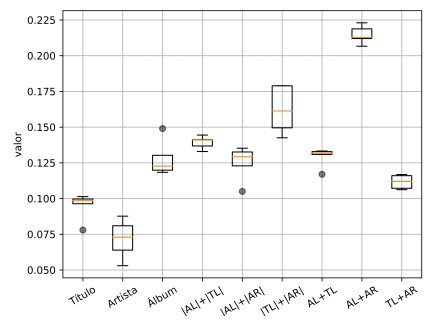

(b) 6000 Músicas

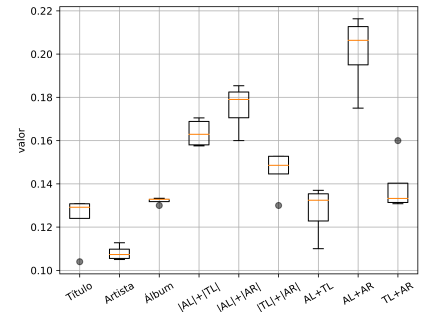

(c) 9000 Músicas

Figura 6: MAP - Gráfico com caixas dos experimentos com 1000 usuários e três variações no número de músicas: 3000,6000 e 9000.

\subsubsection{Amostragem da música}

Os testes realizados com 1000 usuários e as variações no número de obras apresentam, nas Figs. 5 e 6, que no sistema proposto o Experimento 3 obtém os melhores resultados quanto maior o número de composições. $\mathrm{O}$ Experimento 1 obtém os piores resultados, sendo o metadado Artista o com a pior precisão a ser trabalhado de forma isolada. O Experimento 2 obtém bons resultados principalmente no teste da Fig. 5a, onde duas médias das similaridades obtêm os melhores resultados $|T L|+|A R|$ (Título e Artista) e $|A L|+|T L|$ (Álbum e Título). O Experimento 3 no sistema proposto obtém bons resultados com a concatenação dos metadados $A L+A R$ (Álbum e Artista) assim como é possível verificar nos testes das Figs. 5b e 5c, entretanto as outras concatenações dos metadados alcançam resultados menores que o Experimento 2. A Fig. 6 ressalta em sua análise que todos os experimentos obtêm outliers, sendo que a maioria alcançam apenas um outlier com exceção da concatenação dos metadados $A L+T L$ (Álbum e Título) e o metadado isolado Título, assim como é possível visualizar na Fig. 4a que obtém dois outliers. Com exceção dos outliers a variação dos resultados em sua maioria é pequena exceto $|T L|+|A R|$ (Título e Artista) e $|A L|+|T L|$ (Álbum e Título) na Fig. 6a.

\subsection{MRR}

A métrica MRR é utilizada para medir a assertividade do sistema, quanto à primeira música relevante, perante todos os seus usuários e aplicada em todos os experimentos. Nas Figs. 7 a 10 encontram-se os resultados dos testes. Dentre os seis testes realizados, a média da similaridade entre $|A L|+|T L|$ (Álbum e Título) pertencente ao Experimento 2 obtém quatro dos melhores resultados. Assim como o metadado Artista trabalhado isolado obtém cinco dos seis piores resultados no sistema proposto.

\subsubsection{Amostragem do usuário}

Os testes realizados com 10000 músicas e as variações no número de usuários apresentam, nas Figs. 7 e 8, que, no sistema proposto, o Experimento 2 obtém os melhores resultados. Também é possível visualizar, na Fig. 7, que quanto maior a lista de recomendação melhor o sistema se comporta, obtendo assim melhores resultados. O Experimento 1 alcança os piores resultados, ficando sempre com algum metadado com a menor assertividade. Nas Figs. 7a e 8a, entretanto, é possível visualizar que o Título obtém o melhor resultado no teste com 100 usuários, o que não se aplica para os demais testes. O Experimento 2, em todos os testes das Figs. 7 e 8 , obtém com pelo menos uma média da similaridade dos metadados entre os três melhores resultados, sendo que a média da similaridade $|A L|+|T L|$ 


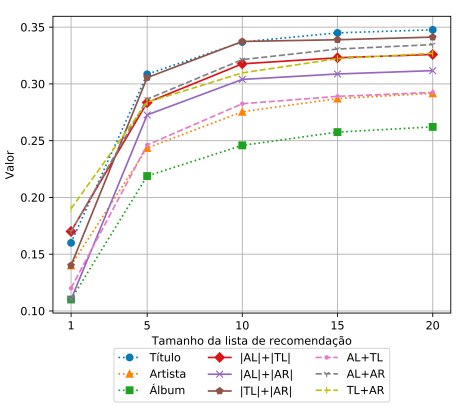

(a) 100 Usuários

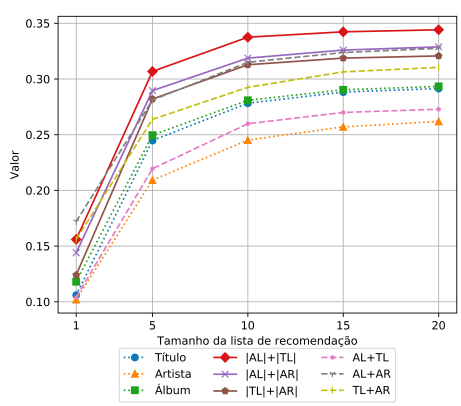

(b) 500 Usuários

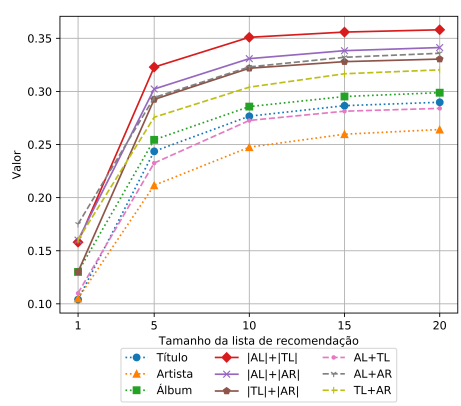

(c) 1000 Usuários

Figura 7: MRR - Gráfico com linhas dos experimentos com 10000 músicas e três variações no número de usuários: 100, 500 e 1000 .

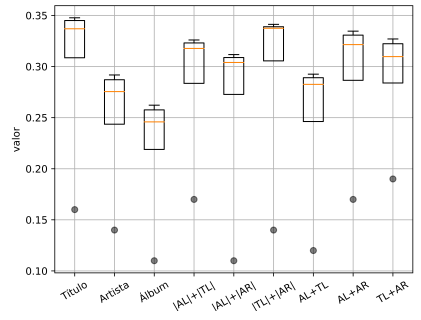

(a) 100 Usuários

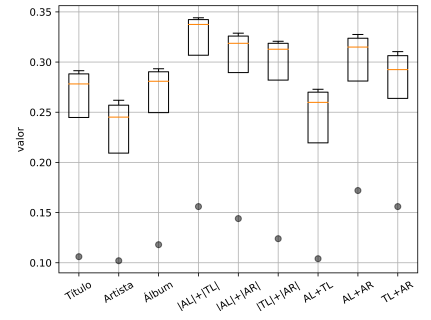

(b) 500 Usuários

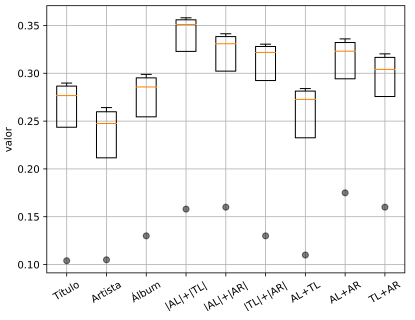

(c) 1000 Usuários

Figura 8: MRR - Gráfico com linhas dos experimentos com 1000 usuários e três variações no número de músicas: 3000,6000 e 9000.

(Álbum e Título) alcança os melhores resultados nos testes das Figs. 7b e 7c. O Experimento 3 no sistema proposto obtém resultados satisfatórios, porém sempre menores que o Experimento 2. A Fig. 8 ressalta em sua análise que todos os experimentos obtêm um outlier apenas, este que corresponde ao valor do MRR para a lista de recomendação com apenas uma canção. A variação dos resultados é aproximadamente igual, sendo que todos os experimentos obtêm melhores resultados quanto maior a lista de sugestões, demonstrando assim uma curvatura de crescimento parecida, como é possível verificar na Fig. 7.

\subsubsection{Amostragem da música}

Os testes realizados com 1000 usuários e as variações no número de obras apresentam, nas Figs. 9 e 10, que no sistema proposto, o Experimento 2 obtém dois dos três melhores resultados em todos os testes. Também é possível visualizar, na Fig. 9, que quanto maior a lista de recomendação melhor o sistema se comporta, obtendo assim melhores resultados. O Experimento 1 obtém os piores resultados, sendo o metadado Artista com o a pior precisão a ser trabalhado de forma isolada. O Experimento 2 obtém os melhores resultados, com exceção do teste da Fig. 9b, onde a concatenação dos metadados $A L+A R$ (Álbum e Artista) do Experimento 3 obtém um resultado melhor seguido de duas médias das similaridades do experimento. A Fig. 10 ressalta em sua análise que todos os experimentos obtêm um outlier apenas, este que corresponde ao valor do MRR para a lista de recomendação com apenas uma música. A variação dos resultados é aproximadamente igual, sendo que todos os experimentos obtêm melhores resultados quanto maior a lista de sugestões, obtendo assim uma curvatura de crescimento parecida, como é possível verificar na Fig. 9.

\subsection{Discussão}

Neste trabalho é mostrado como construir um sistema de recomendação de música com filtragem baseada conteúdo, em um cenário com escassez de informação que descreve a música e encontrar recomendações a partir da similaridade entre os metadados editoriais.

Após analisar os resultados obtidos com as métricas utilizadas, conclui-se que mesmo em um ambiente desbalanceado é possível obter aproximadamente $20 \%$ de assertividade ao longo das listas de recomendações. Quando se usa a concatenação dos metadados $A L+A R$ (Álbum e Artista), o aumento no número de usuários no sistema interfere no resultado da métrica MAP. Não o afeta, porém, de forma brusca, assim como uma lista de recomendação com um número maior de músicas ajuda na obtenção de um melhor resultado. Já quando olhamos para a primeira canção mais relevante, a soma da similaridade $|A L|+|T L|$ (Álbum e Título) comportouse melhor, chegando a mais de $35 \%$ de assertividade. 0 aumento no número de músicas do sistema não inter- 


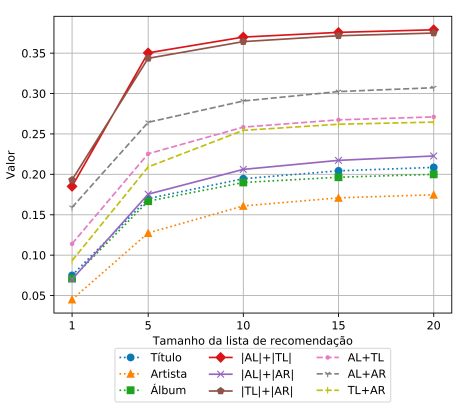

(a) 3000 Músicas

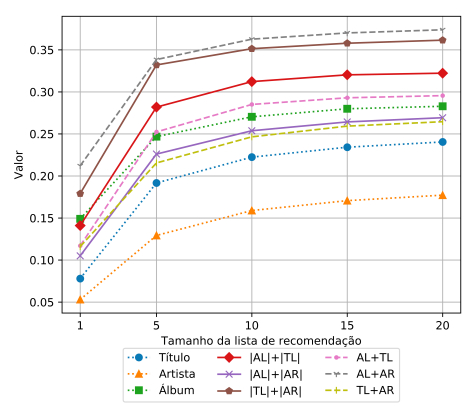

(b) 6000 Músicas

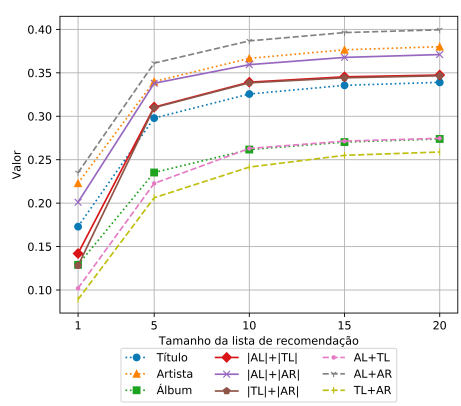

(c) 9000 Músicas

Figura 9: MRR - Gráfico com linhas dos experimentos com 1000 usuários e três variações no número de músicas: 3000,6000 e 9000 .

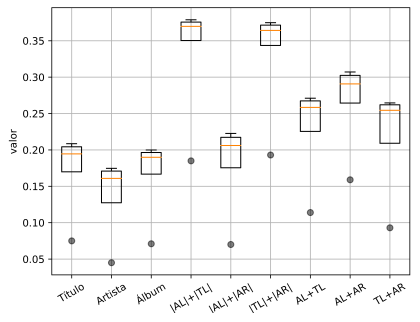

(a) 3000 Músicas

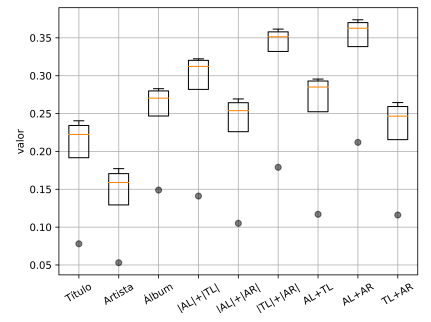

(b) 6000 Músicas

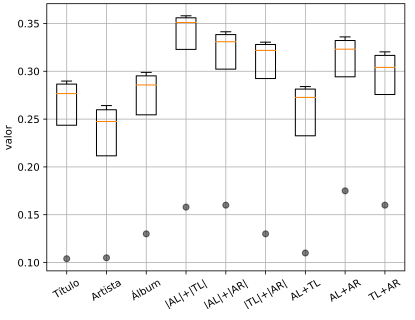

(c) 9000 Músicas

Figura 10: MRR - Gráfico com caixas dos experimentos com 1000 usuários e três variações no número de músicas: 3000,6000 e 9000 .

fere no resultado da métrica MRR, entretanto, a lista de recomendação com um número maior de músicas interfere diretamente no resultado positivo da métrica. $\mathrm{Na}$ maioria dos nossos resultados outliers aparecem, isto é devido a dificuldade de encontrar um item que agrade o usuário na primeira posição da lista de recomendação, causando assim estas variações na assertividade (outliers).

Os resultados obtidos mostram que é possível obter um grau de precisão acima do estratificado, levando em conta que o ambiente trabalhado possuí apenas $11 \%$ de músicas relevantes aos usuários. Assim, obter um resultado da métrica MAP acima de $11 \%$ mostra que o modelo de recomendação proposto consegue recomendar músicas aos usuários em um cenário de escassez de informação de forma satisfatória agradando-os acima do valor esperado (11\%).

\subsection{Pontos de Melhorias}

O principal problema que este trabalho aborda é o cenário com escassez de informação que descreve a música, entretanto, os metadados Título, Álbum e Artista não descrevem a música por completo, podendo, assim, ser complementados com a Letra, Ano e Gênero, e a ainda continuar no cenário com escassez de informação. Aqui, um novo ponto de melhoria aparece. O conjunto de dados do projeto One Million Songs não disponibiliza os metadados Letra e Gênero diretamente, mas eles podem ser mapeados através de pesquisas futuras, sendo necessário realizar uma ligação entre os metadados. Para isto, ter-se-ia que trabalhar com toda a grande massa de dados do projeto, para criar um subconjunto com todas as informações que seriam usadas. Devido a isso, escolheu-se o subconjunto já provido pelo projeto para realização de trabalhos como este.

Outro problema na realização deste trabalho é o tempo de execução dos algoritmos. Como a similaridade é calculada música a música e a recomendação é encontrada a partir da similaridade entre dois modelos que contêm todas as músicas do sistema, realizar esta tarefa não é trivial para os computadores. O limite superior da complexidade de tempo do modelo de recomendação é $\mathcal{O}\left(|U| \times\left|M U_{u}\right| \times\left|M M_{u}\right|\right)$, onde a quantidade de usuários $|U|$ é multiplicada pelo número de músicas no modelo do usuário, multiplicado pelo número de músicas no modelo da música.

Outro ponto de melhoria é o processo de préprocessamento dos metadados em linguagem natural da base de dados. Como as músicas são lançadas em diferentes línguas, o processo de tokenization e derivação precisa identificar a língua daquele metadado, para assim aplicar as tarefas de PLN. Desta forma, atualmente têm-se aplicado apenas às regras do Inglês Norte Americano. 


\section{Conclusão e Trabalhos Futuros}

Este trabalho apresentou um sistema de recomendação de músicas baseado em conteúdo. Inicialmente, foi apresentada a motivação para a criação do sistema de recomendação. Relatou-se o problema de recomendação de músicas em um ambiente com informações escassas. Foi proposta uma solução para ajudar aos usuários a receberem sugestões de sua preferência.

A Seção 2 introduz o referencial teórico. Na Seção 3, apresentou-se trabalhos relacionados. A Seção 4 apresenta e detalha toda a proposta de solução para a recomendação de músicas, inicialmente apresentando os algoritmos usados. Em seguida, apresenta os modelos usados no sistema proposto para encontrar e medir as recomendações. Para finalizar, foi apresentada em detalhes a metodologia na Seção 5 e realizou-se uma avaliação experimental que foi apresentada na Seção 6. Os métodos de avaliação e os resultados foram apresentados, obtendo um grau de precisão acima do estratificado, mostrando que é possível sugerir músicas em um ambiente com escassez de informações.

Como trabalho futuro podemos utilizar alguma aprendizado de máquina binário para classificar se o usuário poderia gostar ou não da recomendação e em um pós-processamento utilizar o nosso modelo de recomendação como algoritmo de reordenação da lista. Outro trabalho futuro é utilizar algum outro algoritmo de similaridade textual no ambiente de escassez de informação e comparar resultados. Outras metodologias de avaliação podem ser utilizadas em um comparativo com os resultados já obtidos.

\section{Referências}

Adomavicius, G. and Tuzhilin, A. (2005). Toward the next generation of recommender systems: A survey of the state-of-the-art and possible extensions, IEEE Transactions on Knowledge \& Data Engineering (6): 734749. https://doi.org/10.1109/TKDE.2005.99.

Bogdanov, D. and Herrera, P. (2011). How much metadata do we need in music recommendation? a subjective evaluation using preference sets, Proceedings of the 12th International Society for Music Information Retrieval, Vol. 12, pp. 97-102.

B.Thorat, P., M. Goudar, R. and Barve, S. (2015). Survey on collaborative filtering, content-based filtering and hybrid recommendation system, International Journal of Computer Applications 110(4): 31-36. Disponível em https://research.ijcaonline.org/volume110/ number4/pxc3900760.pdf.

Burke, R. (2002). Hybrid recommender systems: Survey and experiments, User Modeling and User-Adapted Interaction 12(4): 331-370. http://dx.doi.org/10.1023/ A : 1021240730564 .

Burke, R. (2007). The adaptive web, Springer-Verlag, Berlin, Heidelberg, chapter Hybrid Web Recommender Systems, pp. 377-408. Disponível em: http: //dl.acm.org/citation.cfm?id=1768197.1768211.
Celma, O. (2010). Music Recommendation and Discovery - The Long Tail, Long Fail, and Long Play in the Digital Music Space, Springer. https://doi.org/10.1007/9783-642-13287-2.

Celma, O. and Lamere, P. (2008). If you like the beatles you might like...: A tutorial on music recommendation, Proceedings of the 16th ACM International Conference on Multimedia, MM '08, ACM, New York, NY, USA, pp. 1157-1158. http://doi.acm.org/10.1145/ 1459359.1459615.

DMR (2018). 65 amazing spotify statistics and facts. Disponível em: https://expandedramblings.com/ index.php/spotify-statistics/.

Estadão (2017). Pela primeira vez, streaming lidera receitas da música nos eua. Disponível em: http://link.estadao.com.br/noticias/geral,pelaprimeira-vez-streaming-lidera-receitas-da-musicanos-eua, 70001721714.

Fields, B. (2011). Contextualize Your Listening : The Playlist as Recommendation Engine, PhD thesis, Department of Computing, Goldsmiths, University of London.

Flexer, A., Schnitzer, D., Gasser, M. and Widmer, G. (n.d.). Playlist generation using start and end songs, In Proc. Int. Symposium on Music Information Retrieval (ISMIR-o8.

Forbes (2015). One trillion songs have been streamed so far in 2015. how much larger can this get? Disponível em: https: //www.forbes.com/sites/hughmcintyre/2015/08/13/ one-trillion-songs-have-been-streamed-so-far-in2015-how-much-larger-can-this-get/amp/.

Hijikata, Y., Iwahama, K. and Nishida, S. (2006). Content-based music filtering system with editable user profile, Proceedings of the 2006 ACM Symposium on Applied Computing, SAC '06, ACM, New York, NY, USA, pp. 1050-1057. http://doi.acm.org/10.1145/ 1141277.1141526.

Isinkaye, F., Folajimi, Y. and Ojokoh, B. (2015). Recommendation systems: Principles, methods and evaluation, Egyptian Informatics Journal 16(3): 261 273. "https://doi.org/10.1016/j.eij.2015.06.005".

Knees, P., Pohle, T., Schedl, M. and Widmer, G. (2006). Combining audio-based similarity with web-based data to accelerate automatic music playlist generation, Proceedings of the 8th ACM International Workshop on Multimedia Information Retrieval, MIR '06, ACM, New York, NY, USA, pp. 147-154. http://doi.acm.org/ 10.1145/1178677.1178699.

Logan, B. (2004). Music recommendation from song sets., Citeseer.

Lops, P., de Gemmis, M. and Semeraro, G. (2011). Content-based recommender systems: State of the art and trends, in F. Ricci, L. Rokach, B. Shapira and P. B. Kantor (eds), Recommender Systems Handbook, 
Springer US, pp. 73-105. http://dx.doi.org/10.1007/ 978-0-387-85820-3_3.

Mahieux, B., Ellis, D. P., Whitman, B. and Lamere, P. (2011). The million song dataset, 12th International Society for Music Information Retrieval Conference 2(9): 591-596. Disponível em http:// labrosa.ee.columbia.edu/millionsong/.

Manning, C. D., Raghavan, P. and Schütze, H. (2008). Introduction to Information Retrieval, Cambridge University Press, New York, NY, USA.

McFee, B., Bertin-Mahieux, T., Ellis, D. P. and Lanckriet, G. R. (2012). The million song dataset challenge, p. 909-916. https://doi.org/10.1145/ 2187980.2188222 .

Mladenic, D. (1999). Text-learning and related intelligent agents: A survey, IEEE Intelligent Systems 14(4): 44-54. http://dx.doi.org/10.1109/5254.784084.

Nakamura, K., Fujisawa, T. and Kyoudou, T. (2017). Music recommendation system using lyric network, 2017 IEEE 6th Global Conference on Consumer Electronics (GCCE) pp. 1-2. https://doi.org/10.1109/ GCCE.2017.8229316.

News, D. M. (2018). What streaming music services pay. Disponível em: https://www.digitalmusicnews.com/ 2018/01/16/streaming-music-services-pay-2018/.

Pachet, F. (2003). Content management for electronic music distribution, Commun. ACM 46(4): 71-75. http: //doi.acm.org/10.1145/641205.641207.

Pampalk, E., Pohle, T. and Widmer, G. (2005). Dynamic Playlist Generation Based on Skipping Behavior, Proceedings of the 6th International Conference on Music Information Retrieval, ISMIR, London, United Kingdom, pp. 634-637. https://doi.org/10.5281/ zenodo.1414932.

Parra, D. and Sahebi, S. (2013). Recommender systems: Sources of knowledge and evaluation metrics, in J. D. Velásquez, V. Palade and L. C. Jain (eds), Advanced Techniques in Web Intelligence-2, Vol. 452 of Studies in Computational Intelligence, Springer Berlin Heidelberg, pp. 149-175. http://dx.doi.org/10.1007/978-3642-33326-2_7.

Qin, Y. (2013). A Historical Survey of Music Recommendation Systems: Towards Evaluation, $\mathrm{PhD}$ thesis, Music Technology Area, Department of Music Research, McGill University, Montreal, Canada.

Resnick, P. and Varian, H. R. (1997). Recommender systems, Commun. ACM 40(3): 56-58. http:// doi.acm.org/10.1145/245108.245121.

Ricci, F., Rokach, L., Shapira, B. and Kantor, P. B. (eds) (2011). Recommender Systems Handbook, Springer. https://doi.org/10.1007/978-0-387-85820-3.

Singhal, A. and Google, I. (2001). Modern information retrieval: A brief overview, IEEE Data Engineering Bulletin 24. Disponível em http://sites.computer.org/ debull/A01dec/singhal.ps.
Tiemann, M. and Pauws, S. (2007). Towards ensemble learning for hybrid music recommendation, Proceedings of the 2007 ACM Conference on Recommender Systems, RecSys '07, ACM, New York, NY, USA, pp. 177178. http://doi.acm.org/10.1145/1297231.1297265.

Wang, M., Xiao, Y., Zheng, W., Jiao, X. and Hsu, C. (2018). Tag-based personalized music recommendation, 2018 15th International Symposium on Pervasive Systems, Algorithms and Networks (I-SPAN), pp. 201208. https://doi.org/10.1109/I-SPAN.2018.00040.

Yoshii, K. and Goto, M. (2009). Continuous plsi and smoothing techniques for hybrid music recommendation, ISMIR 2009, 10th International Society for Music Information Retrieval Conference, Proceedings, Citeseer, pp. 339-344. Disponível em http: //ismir2009.ismir.net/proceedings/OS4-1.pdf.

Yoshii, K., Goto, M., Komatani, K., Ogata, T. and Okuno, H. G. (2006). Hybrid collaborative and content-based music recommendation using probabilistic model with latent user preferences, ISMIR 2006, 7th International Conference on Music Information Retrieval, Victoria, Canada, 8-12 October 2006, Proceedings, pp. 296301. 